Petra Fischer · Vormärz und Zeitbürgertum 


\author{
Petra Fischer
}

\title{
Vormärz und Zeitbürgertum
}

\author{
Gustav Albert Lortzings \\ Operntexte
}

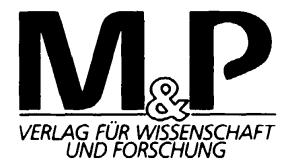


Die Deutsche Bibliothek - CIP-Einheitsaufnahme

\section{Fischer, Petra:}

Vormärz und Zeitbürgertum: Gustav Albert Lortzings Operntexte/ Petra Fischer

- Stuttgart: M und P, Verl. für Wiss. und Forschung, 1996

Zugl.: Heidelberg, Univ., Diss., 1995

ISBN 978-3-476-45165-1

Dieses Werk ist einschließlich aller seiner Teile geschützt. Jede Verwertung außerhalb der engen Grenzen des Urheberrechtsgesetzes ist ohne Zustimmung des Verlages unzulässig und strafbar. Das gilt insbesondere für Vervielfältigungen, Übersetzungen, Mikroverfilmungen und Einspeicherung in elektronischen Systemen.

M \& P Verlag für Wissenschaft und Forschung ein Verlag der J.B. Metzlerschen Verlagsbuchhandlung und Carl Ernst Poeschel Verlag GmbH in Stuttgart

C) 1997 Springer-Verlag GmbH Deutschland

Ursprünglich erschienen bei J.B. Metzlersche Verlagsbuchhandlung und Carl Ernst Poeschel Verlag GmbH in Stuttgart 1997 


\section{DANKSAGUNG}

Die vorliegende Studie hätte nicht geschrieben werden können ohne den Rat und die Hilfe verschiedener Institutionen und Personen, und ich ergreife gerne die Gelegenheit, auf diesem Wege meinen Dank auszudrücken:

Danken möchte ich dem Georg-Richard-Kruse-Archiv der Lippischen Landesbibliothek Detmold und seiner Leiterin Frau Dorothee Melchert, die mich nicht nur sachkundig und unbürokratisch bei meinen Recherchen unterstützte, sondern es auch verstand, eine so angenehme persönliche Atmosphäre zu schaffen, daß ich mich in der Bibliothek immer wie bei Freunden fühlte. Mein Dank gilt ferner Frau Brigitte Höft, der Leiterin der Mannheimer Musikbücherei im Dalberghaus, für ihre großzügige Auslegung der Ausleihfristen. Der Stadt- und Universitätsbibliothek Frankfurt, dem Landesarchiv Berlin sowie der Bayerischen Staatsbibliothek München danke ich für die Möglichkeit, Handschriften einzusehen. Den Mitarbeitern der Bibliotheken des Germanistischen und des Musikwissenschaftlichen Seminars der Universität Heidelberg danke ich ebenfalls für freundliche Unterstützung. Der Universitätsbibliothek Heidelberg habe ich meinen Dank bereits in Form von immensen Mahngebühren abgestattet; sollte davon ein neuer Seitentrakt errichtet werden, würde ich mich freuen, wenn er Lortzings Namen trüge.

Besonders verbunden bin ich der Musikwissenschaftlerin und LortzingExpertin Frau Dr. Irmlind Capelle (Detmold) nicht nur für fachlich wertvollen Rat in mehreren Gesprächen, sondern auch für die uneigennützige Überlassung unpublizierter Forschungsbeiträge, darunter ihrer Dissertation ("Lortzing Werkverzeichnis"), die sie mir Jahre vor Drucklegung zugänglich machte sowie 
Teile der noch unveröffentlichten Briefausgabe ${ }^{1}$. Diese durchaus nicht selbstverständliche Kollegialität hat mir das Leben und Schreiben erheblich erleichtert, und ich bedanke mich herzlich dafür.

Herrn Dr. Jürgen Lodemann (Baden-Baden) danke ich ebenfalls für die freundliche Leihgabe seiner ungedruckten Dissertation, die im Leihverkehr nicht mehr erhältlich ist. Herr Dr. Gerhard vom Hofe (Heidelberg) hat mir frühzeitig die Manuskripte zweier noch unpublizierter Aufsätze zur romantischen Mozartrezeption überlassen. Dafür sei ihm an dieser Stelle herzlich gedankt.

Besonderen Dank schulde ich Herrn Prof. Dr. Dieter Borchmeyer für die Betreuung der Dissertation sowie Herm Prof. Dr. Ludwig Finscher für die Übernahme des Co-Referats.

Die Ermutigung, der Rat und die Zuneigung meiner Freunde war mir wertvoller als ich es mit dürren Worten beschreiben kann. Ich danke ihnen allen, besonders aber Christine Emig und Birgitta Schmid für's Korrekturlesen.

Schließlich möchte ich meiner Familie danken; sie hat in den vergangenen Jahren viel Geduld mit mir bewiesen und sie sich auch von mir verdient. Meinen Eltern sei diese Arbeit gewidmet.

Luzern im August 1996

Petra Fischer

\footnotetext{
${ }^{1}$ Da die historisch-kritische Briefausgabe erst Ende 1995 im Druck erschienen ist, wird im Folgenden noch nach der älteren Ausgabe von Kruse zitiert, soweit sie inhaltlich nicht von der Capelle-Ausgabe abweicht.
} 


\section{INHALT}

\section{EINLEITUNG}

S. 9

\section{LORTZING ALS LIBRETTIST \\ Lortzings "Theorie" des Librettos \\ S. 18 \\ Lortzings literarischer Einflußhorizont}

S. 34

Die Dichter der Vorlagen

S. 49

\section{FRÜHE SING- UND LIEDERSPIELE - VAUDEVILLES}

S. 56

Libretti mit zeitgeschichtlichem Hintergrund: "Ali Pascha" S. 60 -

"Der Pole und sein Kind" S. 70 - "Andreas Hofer" S. 82

Gemütliches und Ästhetisches: "Der Weihnachtsabend" S. 94 "Scenen aus Mozarts Leben" S. 98

\section{DIE KOMISCHE OPER}

S. 116

"Der Amerikaner" (Fragment) S. 122 - "Die beiden Schützen" S. 127 -

"Czaar und Zimmermann" S. 136 -

"Caramo oder das Fischerstechen" S. 146

"Casanova" S. 152 - "Der Wildschütz" S. 158 -

"Der Waffenschmied" S. 176 -

"Zum Großadmiral" S. 183 - "Cagliostro" (Fragment) S. 189 
HANS SACHSENS THEATRALISCHE WANDLUNG

Deinhardstein - Lortzing - Wagner

S. 193

DIE 'ROMANTISCHE OPER'

S. 225

"Undine" S. 227 - "Rolands Knappen" S. 245

DIE KUNST UND DIE REVOLUTION

"Regina"

S. 256

DAS SATYRSPIEL

"Die Opernprobe"

S. 284

LITERATURVERZEICHNIS

Quellen S. 292

Sekundärliteratur S. 296

ABKÜRZUNGSVERZEICHNIS

S. 315 